\title{
Hematoma hepático subcapsular: una complicación inusual posterior a CPRE
}

\author{
Subcapsular hepatic hematoma: an unusual complication following ERCP
}

Mauricio González-Urquijo ${ }^{1}$, Carlos Rodríguez-Montalvo ${ }^{1}$ y Joel O. Jáquez-Quintana ${ }^{1}$

Paciente femenino, de 28 años de edad, es atendida en urgencias, refiriendo dolor abdominal tipo cólico en hipocondrio derecho, acompañado de ictericia, coluria y acolia. Presentaba signo de Murphy $(+)$, ictericia y acolia. Se realiza ultrasonido evidenciando colelitiasis, con colédoco en $7 \mathrm{~mm}$. Pruebas de función hepáticas alteradas, y hemoglobina de $14,5 \mathrm{mg} / \mathrm{dl}$. Se decide realizar colangiografía endoscópica (CPRE), observando un defecto de llenado en colédoco retroduodenal, correspondiente con un lito de $5 \mathrm{~mm}$. Se introduce alambre guía y se realiza barrido con balón. Se realiza colangiografía de control sin defectos de llenado. Finalmente, se realiza esfinterotomía. Se realiza posteriormente colecistectomía por laparoscopia sin complicaciones. A las $24 \mathrm{~h}$, el paciente presenta palidez generalizada, y dolor abdominal 9/10, así como hemoglobina de $8,5 \mathrm{mg} / \mathrm{dl}$. Se realiza endoscopia descartando sangrado por la esfinterotomía. Se realiza TC ab-

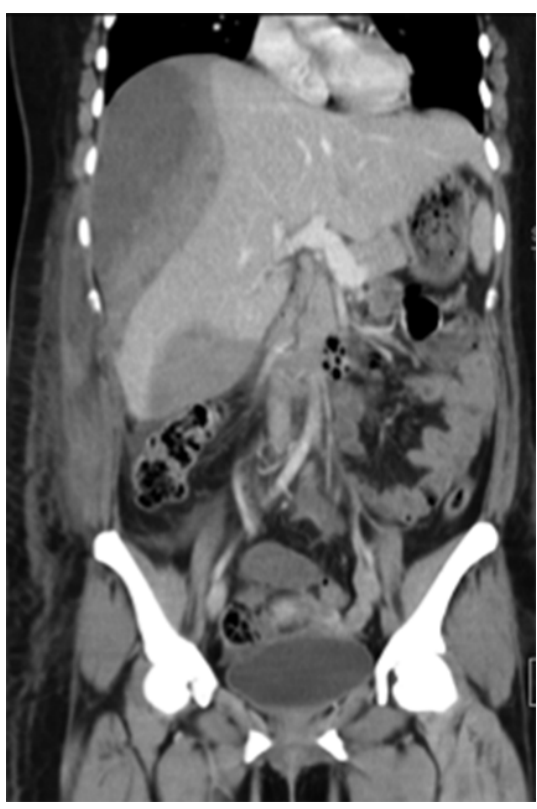

Figura 1. TC de adbomen y pelvis con contraste ev corte coronal. dominal, observando gran hematoma subcapsular de 21 x 12 × $15 \mathrm{~cm}$ (Figuras 1, 2 y 3). Se mantiene en observación por 4 días y, finalmente, se decide su egreso, cursando de forma asintomática. Se ha

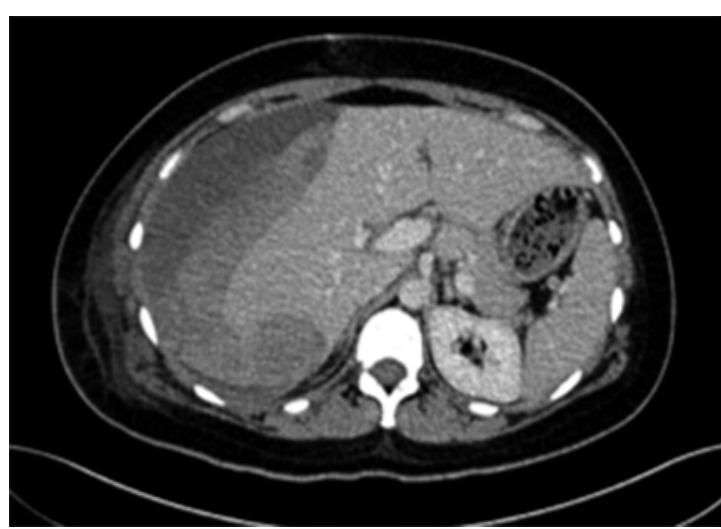

Figura 2. TC de adbomen y pelvis con contraste ev corte axial.
'Tecnológico de Monterrey, Escuela de Medicina y Ciencias de la Salud Monterrey. Nuevo León, México.

Recibido el 31 de diciembre de 2019 y aceptado para publicación el 9 de enero de 2020

Correspondencia a: Dr. Mauricio González-Urquijo mauriciogzzu@gmail.com
Figura 3. TC de adbomen y pelvis con contraste ev corte sagital. 
propuesto como probable causa de esta complicación la lesión del parénquima hepático por la guía ${ }^{1}$. El tratamiento consiste en medidas conservadoras, debiéndose reservar la cirugía para casos con mala evolución ${ }^{2}$.

\section{Responsabilidades éticas}

Protección de personas y animales: Los autores declaran que para esta investigación no se han realizado experimentos en seres humanos o animales.

Confidencialidad de los datos: Los autores declaran que han seguido sus protocolos de sus centros de trabajo sobre la publicación de datos de pacientes y que se ha preservado en todo momento su anonimato.

Derecho a la privacidad y consentimiento informado: Declaramos que se ha conseguido el consentimiento informado del paciente referido en el artículo.

Conflicto de intereses: Los autores declaran no tener conflicto de intereses.

Financiamiento: Este estudio no recibió ningún apoyo específico por parte de agencias de fondos, en el sector público, comercial o sin fines de lucro.

\section{Bibliografía}

1. McArthur KS, Mills PR.

Subcapsular hepatic hematoma after
ERCP. Gastrointest Endosc. 2008;67:37980.

2. Baudet JS, Arguiñarena X, Redondo I, Tadeo E, Navazo L,
Mendiz J, et al. Hematoma hepático subcapsular. Una rara complicación de la CPRE. Gastroenterol Hepatol. 2011;34:7982. 